\title{
A STUDY OF THE FACTORS AFFECTING THE SUCCESS OR FAILURE OF RECRUITMENT AND SELECTION PROGRAM AT REAL ESTATE COMPANY
}

\author{
Dr. Niraj Kishore Chimote \\ Associate Professor, IBS Hyderabad, Telangana, India
}

Kritika Hurla

Student of Master of Business Administration Program (2018-2020), IBS

Hyderabad, Telangana, India

\begin{abstract}
The main focus of this report is to analyze which are the most important factors that affect recruitment process and also to understand the attitude of employees towards recruitment and selection process. The report starts with introduction to industry, objectives of doing this report, theoretical aspects related to recruitment and selection process. Further this report consists of conclusion along with recommendations and the sample questionnaires which have been used for analyses has been attached as appendix.
\end{abstract}

Key words: Recruitment and Selection, Real Estate Industry.

Cite this Article: Niraj Kishore Chimote and Kritika Hurla, A study of the factors affecting the success or failure of recruitment and selection program at real estate company, International Journal of Management, 11(12), 2020, pp. 939-954.

http://iaeme.com/Home/issue/IJM?Volume=11\&Issue=12

\section{INTRODUCTION}

\subsection{Real Estate Industry}

The real estate sector is one of the most globally recognized sectors. Real estate sector comprises four sub sectors - housing, retail, hospitality, and commercial. The growth of this sector is well complemented by the growth of the corporate environment and the demand for office space as well as urban and semi-urban accommodations. The construction industry ranks third among the 14 major sectors in terms of direct, indirect and induced effects in all sectors of the economy.

It is also expected that this sector will incur more non-resident Indian (NRI) investments in both the short term and the long term. Bengaluru is expected to be the most favoured 
A study of the factors affecting the success or failure of recruitment and selection program at real estate company

property investment destination for NRIs, followed by Ahmedabad, Pune, Chennai, Goa, Delhi and Dehradun. The real estate industry can be divided into several different areas:

- Development: Real estate development is a process that involves the purchase of raw land, rezoning, construction and renovation of buildings, and sale or lease of the finished product to end users. Developers earn a profit by adding value to the land (creating buildings or improvements, rezoning, etc.) and taking the risk of financing a project. Development firms create a new product, which can be thought of as the "primary market" or generation of new inventory.

- Sales and marketing: Sales and marketing firms work with developers to sell the buildings and units they create. These firms earn a commission for creating all marketing material and using their sales agents to sell the inventory of completed units. These firms typically focus on new units.

- Brokerage: A real estate brokerage is a firm that employs a team of real estate agents (realtors) who help facilitate a transaction between the buyers and sellers of property. Their job is to represent either party and help them achieve the purchase or sale with the best possible terms.

- Property management: Property management firms help real estate owners to rent out the units in their buildings. Their jobs include collecting rent, showing units, fixing deficiencies, performing repairs, and managing tenants. They charge a fee, typically a percentage of the rent, to property owners.

- Real estate lending: Lenders play a major role in the industry as virtually all properties and developments use leverage (debt) to finance their business. Lenders can include banks, credit unions, private lenders, and government institutions.

- Professional services: There are a variety of real estate professionals who work in the industry and help make it function. The most common examples are accountants, lawyers, interior designers, stagers, general contractors, construction workers, and tradespeople.

\subsection{Recruitment}

Effective recruitment is the process of getting the right kind of people to apply for the vacancies in the organization.

\section{Recruitment Needs}

There are three types of recruitment needs as follows:

- Planned: These types of recruitment needs arise from changes in organization and out of retirement policy.

- Anticipated: Anticipated needs arise due to movements of personnel. An organization can study the trends of movement by analysing internal and external environment and predict the recruitment need.

- Unexpected: Resignation, deaths, accidents, prolonged illness are the primary cause of unexpected recruitment needs.

The basic purpose of recruiting is to develop a group of potentially qualified people. To this end, the organization must communicate the position in such a way that job seekers 
respond. To be cost effective, the recruitment process should attract qualified applicants and provide enough information for unqualified persons to self-select themselves out.

\subsection{Selection}

According to Yoder "The hiring process is of one or many 'go, no-go' gauges. Candidates are screened by the application of these tools. Qualified applicants go on to the next hurdle, while the unqualified are eliminated." The selection process in an organization depends on the organization's strategy and objectives, the tasks and responsibilities successfully.

The selection process, if properly done, will ensure availability of competent employees in the organization. Hence this process is done according to the requirements of the organization. If a wrong candidate is selected or rejected then it can prove to be a costly mistake. Therefore, it's important that the HR department formulates right tools and techniques in order to get the best candidate.

\section{LITERATURE REVIEW}

The introduction section highlighted the various concepts of recruitment and selection. The literature review aims to examine the important variables which affect recruitment and selection procedure at workplace.

\section{- Sinha and Thaly (2013)}

Focus of study - Recruitment approaches to be used depends on the job position.

Sinha and Thaly Noted that there is a variety of recruitment approaches (e.g. employee referral, campus recruitment, advertising, recruitment agencies/consultants, job sites/portals, company websites, social media etc.); and most organizations will use a combination of two or more of these as part of a recruitment process or to deliver their overall recruitment strategy. However, which recruiting channels should be used depends on the job position, on the company's employer brand, on the resources the company has on its recruiting team, on how much recruiting budget the company has, etc. One can use them all and find out which suits the best. Every recruiting channel offers different benefits and limitations and works better for certain situations and companies.

\section{- Priyanath (2006)}

Focus of study - Formal method of recruitment is better than informal method.

Priyanath argues that a major challenge faced is the difficulty in recruiting and selecting employees with the correct qualifications to help achieve goals of the enterprise. He explained further that this problem is compounded by the lack of systematic method for recruiting and selecting employees. A systematic recruitment process involves identifying vacancies, job analysis, job description, person specification and advertising. A systematic selection process involves the recruiting process, gathering information about qualified applicants, evaluating the qualification of each applicant and making decisions about employment. On the contrary, evidence suggests that most organizations follow an informal process for recruiting and selecting employees.

\section{- Swanepoel, 2003}

Focus of study - Job description and Job analysis forms an integral part of HR management.

Job description listing the tasks, duties, and responsibilities of a specific job. Having upto-date, accurate and professionally written job descriptions is critical to an organization's ability to attract qualified candidates, orient $\&$ train employees, establish job performance standards, develop compensation programs, conduct performance reviews, set goals and meet 
A study of the factors affecting the success or failure of recruitment and selection program at real estate company

legal requirements. Prior to the development of the job description, a job analysis must be conducted. Job analysis, an integral part of HR management, is the gathering, analysis and documentation of the important facets of a job including what the employee does, the context of the job, and the requirements of the job. The benefit of having an automated cloud-based system for the maintenance and management of job descriptions include: Effectively collaborate between HR, department heads, managers, and subject matter experts; easily create, edit and maintain job descriptions; retain an archive of job descriptions and maintain up-to-date and accurate job descriptions. The recruiter needs to be objective when determining key performance areas so as to provide the panel with insight into the actual job requirements. This may form part of a job description.

\section{- Galanaki (2002)}

Focus of study - Internet agency provide better applicants than recruitment agency.

Galanaki had conducted a descriptive study on the decision to recruit online, involving 99 UK IT companies whose shares were traded in London stock exchange. A survey was carried out, in the form of a postal questionnaire, followed by an interview to which 34 companies replied. The author found that internet agencies provide the company with fewer but substantially better applicants than traditional recruitment agencies.

\subsection{Research Gaps}

The studies mentioned above shows a very generalized view of the factors which affect the recruitment and selection process at companies. Large and reputed organizations from the real estate industry, requires a more specific study which could help in exploring of the factors which impacts the effectiveness of the recruitment program.

\subsection{Objectives}

Based on the research gaps explored above in the literature review following are the objectives finalized for the report:

- To analyse which are the most important factors that affect recruitment process.

- To understand the attitude of employees towards recruitment and selection process.

\subsection{Variables Identified for Analysis}

The success of recruitment program can be judged based on a number of criteria. Some of these are:

\subsection{Dependent variables}

- No. of successful placements (Garry Dessler,2015): the number of successful placements is the most important criterion for determining the success or failure of a recruitment program. This is the bottomline of the whole program.

- No of hirings (Garry Dessler,2015): If the recruitment program has mot met its objectives in terms of the number of successful placements then other factor like no. of hiring's should be taken into consideration to understand the stage at which any discrepancy has occurred.

- No. of applicants (Garry Dessler,2015): if the number of applicants is less, then there was probably a problem in attracting job seekers. Therefore no. of applicants must be taken into consideration in order to understand discrepancy has occurred due to which the recruitment program has become ineffective. 


\subsection{Independent Variables}

- Reputation of the organization (Garry Dessler, 2015): An organization's reputation depends on its size, area of business, profitability, management etc. in addition to its philosophy and values.

- Organizational Culture (Garry Dessler, 2015): The organizational culture and attitude of its management towards employees influences a candidate's decision to apply to an organization.

- Geographical location of vacant position (Garry Dessler,2015): The success of a recruitment program depends on the geographical location of the organization. Prospective candidate might not be too eager to work in a remote place unless they belong to that place.

- Emoluments offered (Garry Dessler,2015): the emoluments that the company offers also influence the decision of a candidate and thereby the success of the recruitment program.

- Time Available (Garry Dessler,2015): The amount of resources allocated determine the success of recruitment program which in turn is dependent on the criticality of the vacant position and the time available to fill the vacancy.

- Knowledge and skill set (Garry Dessler,2015): The situation in the labour market, demand for manpower, the demographics, the knowledge and skill set available, all determine the response to a recruitment program.

- Legal implications (Garry Dessler,2015): the law of the land and the legal implications involved also play a role in designing a recruitment program and determining its effectiveness.

\section{RESEARCH METHODOLOGY}

The name of the company has not been mentioned to maintain secrecy and confidentiality. Moreover, the NOC of the company couldn't be obtained and therefore the company has been referred to as leading real estate industry in the entire report.

The objectives of the study have been formulated on the basis of gaps found in the literature review. Research methodology is designed in a way so that it helps to achieve the objectives of the study.

In the Encyclopedia of Social Sciences, D. Slesinger and M. Stephenson (1930) defined research as "the manipulation of things, concepts or symbols for the purpose of generalizing to extend, correct or verify knowledge, whether that knowledge aids in the construction of theory or in the practice of an art".

The actual information provided in this report will be collected from two different sources, namely primary and secondary source. The major components of research methodology are:

\subsection{Identifying and Defining the Problem}

The foremost step in research is to identify and define the problem and objectives of the report which have been explained in the earlier part of the report. 
A study of the factors affecting the success or failure of recruitment and selection program at real estate company

\subsection{Methodology for Objective I \& II}

\subsubsection{Research Design (Malhotra \& Dash, 2009)}

A research design is the actual framework of a research that provides specific details regarding the process to be followed in conducting the research. It can be defined as the plan and structure of enquiry formulated in order to obtain answers to research questions. It is a framework or blueprint for conducting the research projects. It specifies the details of the procedures necessary for obtaining the information needed to structure and solve research problems.

\subsubsection{Type of Research Design}

It is very necessary to select an appropriate and specific research design before the actual research work is started. This study is a formal research where the objectives are clearly defined and details about all aspects of problem are collected. Regardless of the problem's complexity, it is important to design this conclusive research efficiently so that it forms the basis for an analytical study that would enable us to develop hypothesis.

\subsubsection{Specification of the measurement and scaling procedures}

The study consists of usage of Likert's scale for measuring the variables. Some of the variables like, reputation, location, emoluments, knowledge and skill set available consist of a series of statements where the respondents have to provide answers in the form of agreement or disagreement. So, the respondent needed to select a numerical score (like 1 or 2 or 3 or 4 or 5) for each statement to indicate the degree of agreement or otherwise. Each score has to be finally added up to measure the respondent's attitude.

\subsubsection{Sampling}

Convenience sampling method has been used for conducting the survey. This is a nonprobability sampling technique and has been used because the accessibility of the population was easy.

\subsubsection{Survey}

It is a research technique which is used to gather information from a sample of respondents by employing a questionnaire to obtain primary data. It is the data which is gathered first hand to answer the research question being investigated. Surveys are done depending on the objectives formulated. It is basically used for collecting data from a pre-defined group of respondents to gain more insights into our topic of interest.

\subsubsection{Description of the questionnaire}

The questionnaire has been prepared on the basis of the variables identified in the Literature review.

- Reputation of the organization

- Organization culture

- Geographical location

- Emoluments offered

- Time available

- Knowledge and skill set

- Legal implications 


\subsubsection{Sample Size Calculations}

The following formula has been used for calculating the sample size

$\mathrm{n}=\mathrm{N}^{*} \mathrm{X} /(\mathrm{X}+\mathrm{N}-1)$,

where,

$\mathrm{X}=\mathrm{Z}_{\alpha / 2}{ }^{2} * \mathrm{p} *(1-\mathrm{p}) / \mathrm{MOE}^{2}$

$Z_{\alpha / 2}=1.96$ for a confidence level of $95 \%$ (Normal Distribution Table)

$\mathrm{MOE}=$ Acceptable level or Margin of error $=0.1$ (Approximately) (Malhotra \& Dash, 2009)

$\mathrm{p}$ is the sample proportion

$\mathrm{N}=60$, the population size.

\subsubsection{Calculations}

$$
\begin{aligned}
& X=(1.96)^{2} * 0.5(1-0.5) /(0.1)^{2} \\
& X=96.04 \\
& n=60 * 96.04 /(96.04+60-1) \\
& N=38
\end{aligned}
$$

\section{Notes}

The sample size has been mentioned below according to the following justification:

- The Margin of error may be assumed as 5 to 10 percent (Malhotra \& Dash,2009).

- When the Margin of error is $10 \%$, Confidence level is $95 \%$ and Population size is 60 , the recommended sample size is 38 .

- Thus, the sample size for the analysis can be reasonably considered to be above 38 respondents.

- As a rough guideline, for formulating the problem in factor analysis, there should be at least four or five times as many observations (sample size) as there are variables (Malhotra \& Dash,2009).

\subsection{Analysis}

\subsubsection{Reliability Analysis}

When the outcome of a measuring process is reproducible and the scale provides stable measures at different times under different conditions, it is termed as Reliability. An analysis has been conducted for checking the reliability of the questionnaire. The Cronbach's alpha (a measure of reliability) has been calculated for the model separately. These coefficients are expected to indicate reliability as they ought to meet the minimum acceptable level of 0.6 (Hair et al., 2007). The details are given in the later part of report.

\subsubsection{Factor Analysis}

It is a set of methods in which the observable responses of individuals on a set of variables are represented as functions of a small number of latent variables called factors. The current study contains large number of variables that would make the analysis and interpretation of the problem difficult. Factor analysis helps to reduce the number of variables to be analyzed into a few factors that may summarize the available data. It is needed to identify the underlying dimensions that would explain the correlations among a set of variables. Along with that, it is also necessary to identify new factors to replace the original set of correlated variables in regression analysis. Thus, factor analysis is needed for all models in this study. Bartlett's test of sphericity has been used to test the null hypothesis that the variables are uncorrelated in the 
A study of the factors affecting the success or failure of recruitment and selection program at real estate company

population through a Chi-square statistic. The factor analysis would be called appropriate if the null hypothesis is rejected. Along with that, Kaiser-Meyer-Olkin (KMO) measure of sampling adequacy has also been tested through an index. Generally, a value greater than 0.5 is desirable for concluding that factor analysis is appropriate. The steps involved in conducting factor analysis (Malhotra \& Dash, 2009) are as follows:

- Step One: Formulation of problem: According to the questionnaire described earlier, the variables used in the analysis are mentioned in this step.

- Step Two: Correlation Matrix: A correlation matrix shows simple correlations between all possible pairs of variables included in the analysis. The diagonal elements which are all 1 are usually omitted. An identity matrix should have all diagonal terms as 1 and all off diagonal terms as 0 . The following is the formulation of Hypothesis.

- Null Hypothesis: Variables are uncorrelated in the population (The population correlation matrix is an identity matrix). In other words, it means that each variable correlate perfectly with itself but has no correlation with other variables. The hypothesis is tested by Bartlett's test of sphericity. The test statistic for sphericity is based on a chi- square transformation of the determinant of the correlation matrix. The chi-square statistic is used only for Bartlett's test of sphericity and its value will help in concluding whether the variables are correlated or not. A large value of the test statistic will favor the rejection of the null hypothesis. Another useful statistic is the Kaiser-Meyer-Olkin (KMO) measure of sampling adequacy which is an index used to examine the appropriateness of factor analysis. High values between 0.5 and 1 indicate factor analysis is appropriate. Values below 0.5 imply that factor analysis may not be appropriate.

- Step Three: Method of Factor Analysis: The factor analysis has been conducted through a method called as Principal-components method as it explains more variance than would the loadings (values that explained how closely the variables were related to each one of the factors discovered) obtained from any other method of factoring. Only in case of principal component analysis is it possible to compute exact factor scores and these scores are uncorrelated with each other. The factor scores can be used instead of the original variables in subsequent multivariate analysis.

- Step Four: Determine the number of factors: While determining the number of factors, it is essential to summarize the information contained in the original variables so that a smaller number of factors should be extracted. An eigen value represents the total variance explained by each factor. In eigen value approach, only factors with eigen value greater than 1 are retained and other factors are not included in the model. Thus, the number of factors has been determined on the basis of eigen values. It is recommended that the factors extracted should account for at least 60 percent of the variance. The total variance explained is the percentage of total variance which can help in understanding how well the factors are able to summarize the data.

- Step Five: Rotation of factors: The un-rotated component matrix describes the relationship between variables and factors. However, it cannot help in interpreting the 
factors effectively because many variables are related with many factors thereby creating a need to simplify the matrix to interpret the factors. The rotation of the component matrix was done to attain a technically simple structure. Varimax rotation was used to maximize the variance of the loadings within each factor to simplify the columns in the factor analysis. It helps in developing clearer factor loading patterns with some variables having high loadings on a particular factor and other variables having a loading nearer to zero. Thus, it facilitates to interpret the factors in a different way.

- Step Six: Interpretation of factors: The results of Varimax rotation are summarized in this step.

\subsubsection{Multiple Regression}

A statistical technique that simultaneously develops a mathematical relationship between two or more independent variables and an interval scaled dependent variable is called as Multiple Regression. The present study, as mentioned earlier, is based on descriptive research and the objective of this study is to find associative relationship between the variables mentioned in each model. Thus, multiple-regression has been used for all models which are described in the latter. After conducting this regression, it was found that some independent variables considered in the study turned out not to be significant. When there are large numbers of independent variables and the researcher suspects that not all of them are significant, stepwise regression may be used. The purpose of stepwise regression is to select, from a large number of predictor variables, a small subset of variables that account for most of the variation in the dependent or criterion variable. It can be useful when the sample size is large in relation to the number of predictors (Malhotra \& Dash, 2009). Thus, stepwise regression has also been used for all the models to clear the doubt regarding the significance of independent variables.

The multiple regression model involves more than one independent variable to estimate the dependent variable. The major benefit of this analysis is that it allows the use of the information available from the factors derived in factor analysis, to estimate the dependent variable with greater accuracy. The three components that summarize the multiple regression analysis are Coefficient of Determination (R Square), ANOVA (Regression as a whole) and Regression Coefficients (Beta Coefficients) (Levin \& Rubin, 2002). The usual procedure in a stepwise regression analysis is to enter or remove variables at each step on the basis of testing whether certain partial correlation coefficients are zero. The following are the components of a multiple regression:

Regression Equation: $Y=\alpha+\beta_{1} F_{1}+\beta_{2} F_{2}+\beta_{3} F_{3}+--------------+\beta_{k} F_{k}$

Where $Y=$ Dependent Variable

$\alpha=$ Intercept.

$\mathrm{F}_{1}, \mathrm{~F}_{2} \mathrm{~F}_{3}, \ldots \mathrm{F}_{\mathrm{k}}=$ Independent Variables (In this study, for better understanding after factor analysis, independent variables have been abbreviated as $\mathrm{F}$ and not $\mathrm{X}$ )

$\beta_{1}, \beta_{2}, \beta_{3}, \ldots \ldots \ldots$

\section{- Inference about an individual slope ( $\beta)$}

Hypotheses $\mathrm{H}_{0}$ : $\beta \mathrm{i}=0$; Null Hypothesis: $\mathrm{F}_{\mathrm{i}}$ is not a significant explanatory variable. $\mathrm{H}_{1}: \beta_{\mathrm{i}} \neq 0$; Alternate Hypothesis: $\mathrm{F}_{\mathrm{i}}$ is a significant explanatory variable. 
A study of the factors affecting the success or failure of recruitment and selection program at real estate company

\section{- Inference about the Regression as a whole using an F-test (ANOVA)}

Hypotheses $\mathrm{H}_{0}: \beta_{1}=\beta_{2}=\beta_{3}=------------\beta_{\mathrm{k}}=0$; Null Hypothesis: Y does not depend upon the $\mathrm{F}_{\mathrm{i}}$ 's.

$\mathrm{H}_{1}$ : at least one $\beta_{\mathrm{i}} \neq 0$; Alternate Hypothesis: $\mathrm{Y}$ depends on at least one of the $\mathrm{F}_{\mathrm{i}}{ }^{\text {'s }}$.

\section{- Coefficient of Multiple Determination (R Square)}

It is a fraction of the proportion of variation in $\mathrm{Y}$, the dependent variable that is explained by the regression line, that is, by Y's relationship with independent variables. It measures how well the multiple regression fits the data.

- t value- A statistic used for testing the significance of explanatory variables

- Standard error of a Regression Coefficient: It is a measure of our uncertainty about the exact value of a regression coefficient.

\section{Notes:}

- Data Collection: The data collection has been done through a survey research. The method of collecting information by asking a set of pre-formulated questions in a pre-determined sequence in a structured questionnaire to a sample of individuals drawn so as to be representative of a defined population is known as survey research.

- Evaluating and analysing the data: The next step is to examine the data collected and convert it into a format which will help in concluding the results and facilitate effective decision making. The data collected has been directly fed into computer for eliminating the possibility of human error. The interpretation of the data has been done on the basis of a statistical package known SPSS.

- Conclusions and inferences: The next stage is summarizing the results obtained in the analysis of data

\section{ANALYSIS OF DATA}

The research methodology described earlier highlighted the various research methods used in the study. The various parameters, terminologies and variables defined in the research methodology had to be inspected, cleaned (making it error-free) and transformed to a suitable format. Thus, the sector-wise analysis of data has been carried out with reference to the objectives of the study and research methodology described to highlight useful information, suggest conclusion and support decision making. All the statistical tables have been given in sequential order below. However, final models of stepwise regression tables have been incorporated in this portion and the complete stepwise regression tables have been given below. The minimum number of responses required should be five times the number of variables (Malhotra \& Dash, 2009). Hence, the break-up of the minimum number of responses has been given in Table 1 as follows: 
Niraj Kishore Chimote and Kritika Hurla

Table 1 Minimum responses required for Factor Analysis

\begin{tabular}{|c|c|c|}
\hline Analysis & $\begin{array}{c}\text { Number of metric } \\
\text { variables }\end{array}$ & $\begin{array}{c}\text { Minimum number of responses } \\
\text { required (Number of Variables*5) } \\
\text { (Malhotra \& Dash,2009) }\end{array}$ \\
\hline $\begin{array}{c}\text { Success \& Failure of } \\
\text { Recruitment }\end{array}$ & 10 & 50 \\
\hline Total & 10 & 50 \\
\hline
\end{tabular}

\subsection{Reliability Analysis}

The survey questionnaire had to be tested for its reliability. An analysis was conducted for checking the reliability of the questionnaire and the results were obtained. The Cronbach's alpha (a measure of reliability) score has been calculated for all the analyses. The results have been summarized in Table 2 as mentioned below. The values of Cronbach's alpha above 0.6 indicate that there is internal consistency in the data.

Table 2 Cronbach's alpha score

\begin{tabular}{|c|c|}
\hline \multicolumn{2}{|c|}{ Reliability Statistics } \\
\hline Cronbach's Alpha & N of Items \\
\hline .582 & 7 \\
\hline
\end{tabular}

\subsection{Factor Analysis}

- Step One: According to the questionnaire described earlier, the following are the variables used in this analysis: Reputation, Culture, Legality, Location, Emoluments, Knowledge \& Skill set.

- Step Two: Null Hypothesis: Variables are uncorrelated in the population (The population correlation matrix is an identity matrix). From Table 3, the Approx. Chi-Square value is 135.199 and it has found to be significant which indicates that the null hypothesis can be rejected and it may be concluded that variables are correlated in the population. The chi-square statistic is used only for Bartlett's test of sphericity and its value will help in concluding whether the variables are correlated or not. The Kaiser-Meyer-Olkin (KMO) measure of Sampling Adequacy is found out to be 0.504 which indicates that factor analysis is appropriate.

Table 3 KMO and Bartlett's Test

\begin{tabular}{|l|l|r|}
\hline \multicolumn{2}{|l|}{ Kaiser-Meyer-Olkin Measure of Sampling Adequacy. } & .504 \\
\hline Bartlett's Test of Sphericity & Approx. Chi-Square & 135.199 \\
\cline { 2 - 3 } & Df & 21 \\
\cline { 2 - 3 } & Sig. & .000 \\
\hline
\end{tabular}

Ho: The sample size is adequate

Ha: The sample size is inadequate 
A study of the factors affecting the success or failure of recruitment and selection program at real estate company

- Step Three: The factor analysis has been conducted through a method called as Principal-components method.

- Step Four: Determine the number of factors: It is observed from Table 4, that the total variance explained is $63.627 \%$.

Table 4 Total Variance Explained

\begin{tabular}{|c|c|c|c|c|c|c|c|c|c|}
\hline \multirow[b]{2}{*}{$\begin{array}{c}\text { Compone } \\
\mathrm{nt}\end{array}$} & \multicolumn{3}{|c|}{ Initial Eigenvalues } & \multicolumn{3}{|c|}{$\begin{array}{c}\text { Extraction Sums of Squared } \\
\text { Loadings }\end{array}$} & \multicolumn{3}{|c|}{$\begin{array}{c}\text { Rotation Sums of Squared } \\
\text { Loadings }\end{array}$} \\
\hline & Total & $\begin{array}{c}\% \text { of } \\
\text { Variance }\end{array}$ & $\begin{array}{c}\text { Cumulati } \\
\text { ve } \%\end{array}$ & Total & $\begin{array}{c}\% \text { of } \\
\text { Variance }\end{array}$ & $\begin{array}{l}\text { Cumulati } \\
\text { ve } \%\end{array}$ & Total & $\begin{array}{c}\% \text { of } \\
\text { Varianc } \\
\mathrm{e}\end{array}$ & $\begin{array}{c}\text { Cumulati } \\
\text { ve } \%\end{array}$ \\
\hline 1 & 3.295 & 47.069 & 47.069 & 3.295 & 47.069 & 47.069 & 2.496 & 35.655 & 35.655 \\
\hline 2 & 1.159 & 16.558 & 63.627 & 1.159 & 16.558 & 63.627 & 1.958 & 27.972 & 63.627 \\
\hline 3 & .893 & 12.764 & 76.391 & & & & & & \\
\hline 4 & .660 & 9.425 & 85.816 & & & & & & \\
\hline 5 & .606 & 8.662 & 94.478 & & & & & & \\
\hline 6 & .272 & 3.881 & 98.360 & & & & & & \\
\hline 7 & .115 & 1.640 & 100.000 & & & & & & \\
\hline
\end{tabular}

- Step Five: The Table 5 displays the Varimax rotation matrix.

Table 5 (Varimax) Rotated Component Matrix

\begin{tabular}{|c|c|c|}
\hline \multirow{2}{*}{} & \multicolumn{2}{|c|}{ Component } \\
\cline { 2 - 3 } & 1 & 2 \\
\hline Reputation & .005 & -.815 \\
\hline Culture & .646 & .259 \\
\hline Location & .377 & .714 \\
\hline Time available & .256 & .716 \\
\hline Emoluments & .839 & -.073 \\
\hline Legal Issues & .703 & .325 \\
\hline Knowledge \& Skill set & .820 & .305 \\
\hline
\end{tabular}

- Step Six: Interpretation of factors: The results of Varimax rotation are summarized in Table 6: 
Table 6 Summary Table of Factors

\begin{tabular}{|c|c|}
\hline Factor 1 & Factor 2 \\
\hline Reputation & \\
\hline Culture & Location \\
\hline & Time available \\
\hline Emoluments & \\
\hline Legal issues & \\
\hline Knowledge \& Skill Set & \\
\hline
\end{tabular}

Factor 1: The following are the variables (Item numbers 1, 2, 5, 6 and 7 from the Questionnaire) that have the highest loading on factor 1 after rotation. This factor has been named as Official Factors as all the variables are related to the workplace.

In order to make to the organization more appealing to the candidate, it must portray and communicate its strength through employee value proposition, which will talk about work culture, empowering employee through various training programs and remunerations.

Factor 2: The following are the variables (Item Numbers 3, and 4 from the Questionnaire) that have the highest loading on factor 2 after rotation. This factor has been named as External Factors.

Travelling time and location can majorly impact the decision of the applicant as one would also prefer a more developed locality and the ease of accessibility.

\subsection{Multiple Regression}

A multiple regression analysis was used to obtain the results. The results of the factor analysis $\left(F_{1}\right.$, and $\left.F_{2}\right)$ were carried forward by which all the independent variables $\left(F_{1}\right.$ and $\left.F_{2}\right)$ were used to predict the dependent variable by multiple regression. The regression equation (Levin \& Rubin, 2002) is as follows: $Y=\alpha+\beta_{1} F_{1}+\beta_{2} F_{2}$

Where $\mathrm{Y}=$ Mean (Mean of the three variables namely No. of applicants, No. of hiring and No. of successful placements

$$
\begin{aligned}
& \alpha=\text { Intercept. } \\
& F_{1}=\text { Official Factors } \\
& F_{2}=\text { External Factors } \\
& \beta_{1}, \beta_{2}=\text { Slopes associated with } F_{1}, F_{2}
\end{aligned}
$$

\section{Inference about the Regression as a whole using an F-test}

Null Hypothesis: $Y$ does not depend upon the $F_{i}$ s s i.e. $H_{0}: \beta_{1}=\beta_{2}=\beta_{3}=------------\beta_{k}=0$

Alternate Hypothesis: $Y$ depends on at least one of the $F_{i}$ s s i.e. $H_{1}$ : at least one $\beta_{i} \neq 0$

Tables 7, 8 and 9 are based on model 1 which has emerged out as an acceptable model in the Stepwise Regression Analysis. The tables also show the relationship between each of these variables. 
A study of the factors affecting the success or failure of recruitment and selection program at real estate company

Factor 1 (Reputation, Culture, Emoluments, Legal Implications, Knowledge and Skill Set,) is statistically significant.

Table 7 Model Summary

\begin{tabular}{|c|c|c|c|c|}
\hline Model & $\mathrm{R}$ & R Square & Adjusted R Square & $\begin{array}{c}\text { Std. Error of the } \\
\text { Estimate }\end{array}$ \\
\hline 1 & $.402^{\mathrm{a}}$ & .162 & .124 & .57331 \\
\hline
\end{tabular}

Table 8 F-test

ANOVA $^{\mathrm{a}}$

\begin{tabular}{|c|c|c|c|c|c|c|}
\hline \multicolumn{2}{|c|}{ Model } & Sum of Squares & df & Mean Square & F & Sig. \\
\hline \multirow{3}{*}{1} & Regression & 2.791 & 2 & 1.396 & 4.246 & $.021^{\mathrm{b}}$ \\
\cline { 2 - 7 } & Residual & 14.462 & 44 & .329 & & \\
\cline { 2 - 8 } & Total & 17.253 & 46 & & & \\
\hline
\end{tabular}

It can be concluded from the above tables indicate that null hypothesis can be rejected and thus $\mathrm{Y}$ depends on at least one of the $\mathrm{F}_{\mathrm{i}}$ 's.

\section{Inference about an individual slope ( $\beta$ )}

Null Hypothesis: $F_{i}$ is not a significant explanatory variable i.e. $\mathrm{H}_{0}: \beta_{\mathrm{i}}=0$

Alternate Hypothesis: $F_{i}$ is a significant explanatory variable i.e. $H_{1}: \beta_{i} \neq 0$

Table 9 Regression Coefficients

Coefficients $^{\mathrm{a}}$

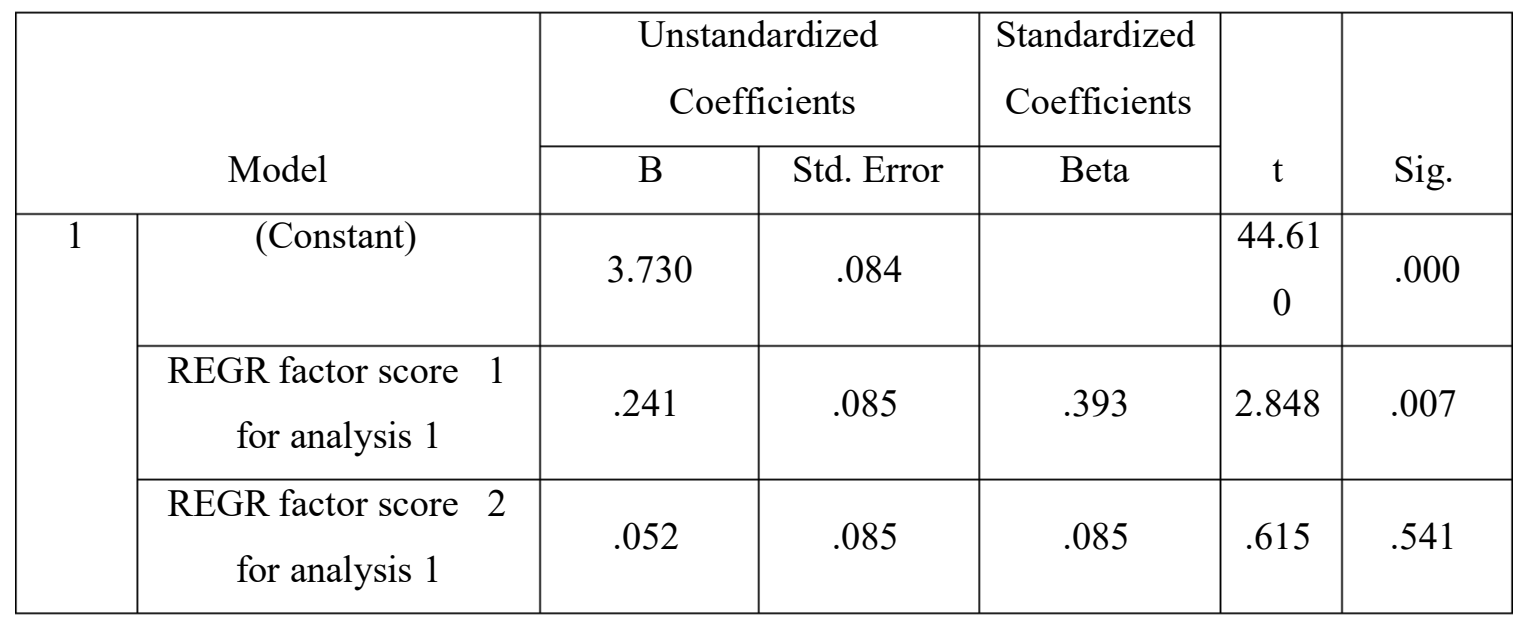

\section{Conclusion:}

Since we use alpha value to be 0.05 to test for the significance of independent variables. Hence, factor 1 is significant as its $p$ value i.e. 0.007 is less than alpha (0.05). Consequently, we see that factor 2 is insignificant as its $\mathrm{p}$ value, i.e. 0.541 is greater than alpha.

The regression equation is found out to be:

$$
\mathrm{Y}=3.73+0.241 \mathrm{~F}_{1}
$$


It can be concluded from the above tables that null hypothesis can be rejected and $F_{1}$, is significant explanatory variable.

Thus, recruitment and selection decision depends on the variables $\left(F_{1}\right.$ and $\left.F_{2}\right)$ as mentioned above. The coefficient of (multiple) determination $\left(\mathrm{R}^{2}\right)$ is 0.162 and the F-ratio is found to be 4.246, which is significant. Thus, one can conclude that regression model is significant to explain the recruitment and selection.

\section{CONCLUSIONS AND DISCUSSIONS}

The objective conclusion obtained on the basis of the research objectives derived, research methodology stated and analyses of data described, are as follows:

\subsection{Objectives}

- To analyse which are the most important factors that affect recruitment process.

- To understand the attitude of employees towards recruitment and selection process.

\subsection{Conclusion}

The factors extracted in this analysis is Official Factors. The recruitment decision depends on these Official Factors. It indicates that the reputation, location, emoluments, legal implications, knowledge and skill set available affects recruitment and selection procedure in the firm.

\subsection{Limitations}

The results obtained in this study are subject to some limitations as mentioned below:

- This is not a comparative study.

- Since the responses were recorded on a Likert scale, there were no available means to verify the accuracy of the data collected. Thus, it was assumed that the data was error free.

- The data collected is cross sectional

\section{QUESTIONNAIRE}

Full Name:

Role:

Email -

Date -

\begin{tabular}{|c|c|c|c|}
\hline \multicolumn{4}{|c|}{$\begin{array}{l}\text { On a scale of (1) Strongly disagree (2) Disagree (3) Neither agree nor disagree (4) Agree (5) } \\
\text { Strongly agree, please circle (O) the appropriate rating. }\end{array}$} \\
\hline $\begin{array}{l}\text { 1. The reputation of the company helps in attracting the applications for the } \\
\text { vacant position in your company. }\end{array}$ & & 2 & \\
\hline $\begin{array}{l}\text { 2. The organizational culture and attitude of its management towards } \\
\text { employees influenced your decision to apply in this organization. }\end{array}$ & & 2 & \\
\hline $\begin{array}{l}\text { 3. The geographical location of your organization contributes towards the } \\
\text { successful placements. }\end{array}$ & & 2 & \\
\hline $\begin{array}{l}\text { 4. Criticality of the vacant position and time available to fill the vacancy } \\
\text { affects the offers made for the job seekers at your organization. }\end{array}$ & & 2 & \\
\hline
\end{tabular}


A study of the factors affecting the success or failure of recruitment and selection program at real estate company

\begin{tabular}{|c|c|c|c|c|c|}
\hline $\begin{array}{l}\text { 5. The emoluments that the company offers influenced your decision and } \\
\text { thereby the success of recruitment program. }\end{array}$ & 1 & 2 & 3 & 4 & \\
\hline $\begin{array}{l}\text { 6. The legal implications involved in designing a recruitment program affects } \\
\text { the time involved in filling the vacant positions. }\end{array}$ & 1 & 2 & 3 & 4 & 5 \\
\hline $\begin{array}{l}\text { 7. Knowledge and skill set available in the external environment influences the } \\
\text { number of hiring's made in the organization. }\end{array}$ & 1 & 2 & 3 & 4 & 5 \\
\hline $\begin{array}{l}\text { 8. Every hiring at your organization results into successful placement at right } \\
\text { position and right profile. }\end{array}$ & 1 & 2 & 3 & 4 & 5 \\
\hline $\begin{array}{l}\text { 9. No. of hirings are decided every year on basis of actual HR planning } \\
\text { activities conducted. }\end{array}$ & 1 & 2 & 3 & 4 & 5 \\
\hline $\begin{array}{l}\text { 10. No. of applicants are decided on the basis of proper job analysis activities } \\
\text { conducted at your organization. }\end{array}$ & 1 & 2 & 3 & 4 & \\
\hline
\end{tabular}

\section{Signature}

\section{REFERENCES}

[1] European Journal of Business and Management www.iiste.org ISSN 2222-1905 (Paper) ISSN 2222- 2839 (Online) Vol.6, No.1, 2014

[2] Garry Dessler (2015). Human Resource Management- $15^{\text {th }}$ ed. Pearson Education India.

[3] Global Journal of Human Resource Management Vol.3, No.2, pp.22-33, March 2015. Published by European Centre for Research Training and Development UK (www.eajournals.org).

[4] Galanaki, E. (2002), "The decision to recruit online: a descriptive study", Career Development International, Vol. 7 No. 4, pp. 243-251.

[5] Malhotra, N. and Dash, S. (2009) "Marketing Research: An Applied Orientation", Pearson Prentice Hall, Fifth Edition

[6] Ruhuna Journal of Management and Finance Volume 1 Number 1 - January 2014 ISSN 22359222

[7] Slesinger, D. and Stephenson, M. (1930) The Encyclopaedia of Social Sciences. Vol. IX, MacMillan

[8] Sample size calculator: Formula for calculating sample size [online] Retrieved from http://www.raosoft.com/samplesize.html 